\title{
PROCESSO CRIATIVO DE FLÁVIO DE CARVALHO PARA SUA EXPERIÊNCIA N³
}

\author{
Flavio Roberto Lotufo ${ }^{1}$
}

\section{Introdução}

O presente trabalho, baseia-se em pesquisa historiográfica, e tem como escopo a elaboração de uma leitura sobre a performance denominada Experiência $\mathbf{n}^{\mathbf{0}} \mathbf{3}$, realizada pelo artista e engenheiro-arquiteto Flávio de Carvalho (1901 - 1977), em 18 de outubro de 1956, na cidade de São Paulo. Nessa data, o artista vestindo uma blusa de mangas curtas, saia acima dos joelhos, meias arrastão, sandálias de couro e chapéu de náilon, desfilou pelas ruas centrais da capital paulistana, propondo uma nova concepção de traje para os homens tropicais.

O estudo desse evento artístico, está firmou-se em três pontos, quais sejam:

Em primeira instância, o foco da pesquisa direcionou-se para os artigos, de autoria de Flávio de Carvalho, publicados no jornal Diário de São Paulo entre os dias 04 de março e 21 de outubro de 1956. Nesses textos, que anteciparam a Experiência $\mathbf{n}^{\circ} \mathbf{3}$, o autor fez reflexões sobre as transformações sofridas pela indumentária, através da história. A leitura desses artigos buscou levantar pontos indiciais, ali inseridos, que esboçassem o processo criativo da personagem central desta pesquisa, até o seu pensar sobre cada uma das peças concebidas e vestidas por ele durante sua performance.

Flávio de Carvalho elaborou, nesse período, 39 textos abordando a História da Moda. Das modificações das formas femininas e masculinas, passando pelos vários formatos de calçados e adornos de cabeça, até o surgimento de peças específicas como as calças e a casaca, fez ele um levantamento da indumentária desde os tempos dos homens primitivos até os anos 50 do século XX, tendo como base a própria História, a Sociologia, a Psicologia, a Biologia e outras ciências pesquisadas pelo artista. No decorrer desses textos, o autor tece teorias que explicariam as várias transformações sofridas pelas vestimentas femininas e masculinas, apoiando-se nas obras de Charles Darwin, Sigmund Freud, Sir Frazer e Nietzsche.

No trabalho, em questão, optou-se por uma análise apenas da versão completa dos artigos publicados sob o título A Moda e o Novo Homem - Flávio de Carvalho, inclusa na série Modos da Moda organizada pelo SESC/SENAC em outubro de 1992. As considerações do artista estarão sendo cotejadas com estudos sobre História da Moda elaborados por James Laver, Carl Köhler, Anne Hollander, Gilles Lipovetsky, e J.C. Flügel, sendo este último um dos autores estudado pelo artista.

Em um segundo momento, procedeu-se um estudo dos desenhos elaborados por Flávio, que serviram de ilustrações para seus artigos. $O$ olhar direcionado para essa produção específica, objetivou encontrar paralelos entre os croquis, e as formas das peças criadas e vestidas pelo artista durante a Experiência $\mathbf{n}^{\circ}$ 3. Flávio de Carvalho foi buscar em obras de arte de vários períodos e civilizações, referências para criar seus desenhos, e por esse motivo, nesta pesquisa fez-se, quando possível, uma comparação entre a obra de arte inspiradora e a correspondente ilustração elaborada pelo artista. A finalidade desse cotejamento firmou-se, também, na busca de indícios nos desenhos que levassem ao traje usado durante a performance.

\footnotetext{
${ }^{1}$ Mestrado em Produção, Teoria e Crítica em Artes Visuais, Faculdades Santa Marcelina, orientadora: Dra. Mirtes Cristina Marins de Oliveira.
} 


\section{A Experiência $\mathbf{n}^{\circ} 3$}

No dia de sua performance, Flávio de Carvalho saiu do no 297 da rua Barão de Itapetininga, onde mantinha seu ateliê, e percorreu as ruas Marconi, D. José de Barros, Conselheiro Crispiniano, chegando a rua 7 de Abril até o saguão da sede do jornal Diários Associados. Sua vestimenta constava de uma blusa amarela de mangas curtas, uma saia verde de comprimento acima dos joelhos, juntamente com meias arrastão, sandálias de couro e um pequeno chapéu de náilon branco transparente.

A performance foi o ápice da série de 39 artigos escritos por Flávio de Carvalho, publicados pelo jornal Diário de São Paulo, às quintas-feiras e aos domingos, entre 04 de março a 21 de outubro de 1956 com o título “A Moda e o Novo Homem”.

De acordo com Jorge Glusberg a performance é uma expressão artística que tem relação com o Futurismo surgido na Itália, França e Rússia e influências do Dadaísmo e Surrealismo e da Bauhaus, sendo que sua

origem remonta aos rituais tribais, passando pelos mistérios medievais, chegando aos espetáculos organizados por Leonardo da Vinci, no século XV e Giovanni Bernini², duzentos anos mais tarde.

Glusberg faz um mapeamento da arte da performance e para tanto cita aqueles artistas que centram suas investigações no corpo, para exaltar suas qualidades plásticas, medir sua resistência e energia, desvelar seus pudores e inibições sexuais ou os poderes gestuais. Essas experimentações podem, segundo Glusberg, focar situações exteriores como as esculturas vivas, cerimônias litúrgicas ou experiências com figurinos ${ }^{3}$, como fez o artista em estudo. Para Glusberg a arte da performance não está dissociada de uma questão social, sendo que muitas vezes é exatamente o foco centrado pelo artista performático, contando, também com o elemento inesperado, não apenas para o espectador como também para o próprio artista ${ }^{4}$.

Flávio de Carvalho foi influenciado artisticamente por idéias surrealistas, principalmente vindas de pesquisas de Salvador Dali, como bem aponta Valeska de Freitas ${ }^{5}$ quando compara as obras dos dois artistas. Da obra de Dali, Valeska cita o Mito trágico Del "Ângelus" de Millet, e traça paralelos entre a incessante busca de Dali pelas imagens da obra "Ângelus" e as Experiências 2 e 3, e a conseqüente configuração das obras dos dois artistas, que foram divididas entre texto, imagem e performance. Em nota de rodapé ${ }^{6}$, Valeska observa que tanto Dali quanto Flávio, utilizaram o corpo como suporte para suas experimentações artísticas, pois o primeiro deixou-se fotografar vestindo o Ângelus de Millet e o segundo usou uma boina quando da Experiência n ${ }^{\circ} 2$ e vestiu seu Traje de Verão em sua Experiência $n^{\circ} 3$.

Flávio de Carvalho teve contatos diretos com artistas europeus de formação surrealista como o próprio Salvador Dali, Francis Picabia, Man Ray, Tristan Tzara, Alberto Giacometti e André Breton quando freqüentou o Café de La Place Blanche, em Paris, como artista e jornalista correspondente ${ }^{7}$ no período em que esteve naquela cidade no ano de 1934.

\footnotetext{
2 Jorge GLUSBERG. A Arte da Performance. p. 12.

3 Ibid., ps. 46/47.

4 Ibid., p. 83.

${ }^{5}$ Valeska FREITAS. Dialética da Moda: A Máquina Experimental de Flávio de Carvalho. ps. 41/42.

${ }^{6}$ Valeska FREITAS. Dialética da Moda. A Máquina Experimental de Flávio de Carvalho. NR 105, p. 42.

${ }^{7}$ J. TOLEDO. Flávio de Carvalho, O Comedor de Ilusões. p. 276.
} 
Percebeu-se, ainda, influências dadaístas na formação artística da personagem em foco, conforme atestam seus estudiosos que norteiam esta pesquisa. Dawn Ades $^{8}$ distingue duas formas de manifestações dadaístas, sendo uma, a ênfase na busca de uma nova arte para substituir uma estética gasta, como no trabalho de Arp. Outra forma de expor idéias dadaístas é feita pela destruição através da zombaria, explorando a ironia, como nos trabalhos de Tzara e Picabia, apontados por Ades ${ }^{9}$. Exatamente nesse nicho, o da ironia e zombaria é que podemos incluir as performances de Flávio de Carvalho, como manifestações com fortes influências dadaístas.

\section{A dialética da moda}

No artigo publicado no Diário de São Paulo em 24 de junho de 1956, com o título Moda Verão Para a Cidade ${ }^{10}$, Flávio inicia sua proposta para uma nova forma de vestimenta masculina, alegando que a maneira de vestir dos homens daquela época, era a sobrevivência da calça, colete (...) originários do século XVII, mantendo as cores escuras impostas à burguesia pela nobreza como condição depreciativa. Esse modo de trajar, segundo o autor, não estaria de acordo com os conhecimentos do homem contemporâneo e com seu desenvolvimento cerebral. Em continuação a sua idéia sobre adequação da indumentária, alega, ainda, que a vestimenta, criada por ele, considera a ventilação do corpo, possibilitando que o suor pudesse ser evaporado com maior rapidez e continua sua proposta:

A velocidade do fluxo de ar entre o tecido e o corpo é graduável por meio de dois círculos de arame: um na cintura e outro sobre a clavícula. Estes dois círculos preenchem também a função de conservar o tecido de malha aberta afastado do corpo. O tecido leve de cor viva que se encontra por baixo é conservado afastado do corpo por meio de presilhas volantes que são colocadas sobre o tecido de malha aberta do blusão. Estas presilhas são colocadas por último na toilete do cidadão prestes a sair.

Analisando as teorias propostas pelo autor, nos textos sobre moda, deparamos com indícios que levam a uma melhor compreensão do caminho percorrido por Flávio de Carvalho até o protótipo final de seu New Look e a conseqüente Experiência $n^{\circ} 3$, tais como: o desenho do decote da blusa, a escolha de uma peça que deixasse as pernas à mostra, a forma da saia e da blusa e até mesmo a opção por vestir meias arrastão juntamente com sandálias.

\section{A pesquisa dos textos}

Dos 39 textos sobre moda, selecionou-se, para esta pesquisa, dez artigos em que o artista trata de maneira mais explícita as transformações da indumentária masculina e as mudanças das formas do vestuário feminino, no decorrer da história. Tal seleção justifica-se pelo fato de constarem nesses trabalhos, conceitos desenvolvidos pelo artista, que explicariam a concepção e o desenvolvimento da modelagem das peças do Traje de Verão.

\footnotetext{
${ }^{8}$ Dawn ADES. Dada e Surrealismo. Conceitos de Arte Moderna. ps. 81/83.

${ }^{9}$ Ibid., p. 83.

${ }^{10}$ Flávio de CARVALHO, Flávio. A Moda e o Novo Homem. p.66
} 


\section{O homem em farrapos}

Flávio de Carvalho encontra suporte para desenvolver sua teoria sobre as ligações entre o uso de farrapos e a volta aos antepassados quando os homens vestiam-se com longas peles de animais, nas observações de Fraser, quando este assim descreve os trajes de luto usados pelos Maoris ${ }^{11}$ : vestidos de trapos (...) fedendo à óleo de tubarão, solitários e silenciosos, geralmente velhos, (...) descabelados, com freqüência loucos ${ }^{12}$, esses homens eram vistos sentados imóveis sem participar das atividades do resto do grupo,

Para Flávio os homens vestidos em farrapos estariam no grau mais baixo da hierarquia, pois este é um desclassificado na escala social, afirmando que o homem em farrapos é, em todos os tempos, uma apresentação do estado inferior do antepassado antigo ${ }^{13}$. Quando esse homem veste-se dessa maneira, está em contraste àquele investido de autoridade, mas ao mesmo tempo está liberto da disciplina hierárquica, aproximando-se, então dos primeiros homens livres e libertos do princípio da história. Esse traje, segundo o autor, é uma maneira de aproximação com a memória do antepassado. Para o artista essa aparência de pobreza faz o homem reverter-se ao estado inferior da evolução da espécie.

Percebe-se nesse conceito uma aproximação com as teorias evolucionistas de Charles Darwin. A teoria fundamental do naturalista inglês é a de que a luta pela vida e a seleção natural são mecanismos essenciais para a evolução das espécies. Encontram-se na obra $A$ Origem das Espécies, escrita por Darwin em $1859^{14}$, os fundamentos de seus estudos onde diz que dentro das espécies, aqueles indivíduos melhor adaptados a seu meio ambiente geram descendentes, que pela seleção natural vão se transformando e diversificando e, assim produzindo seres mais complexos e cada vez melhor inseridos em seu habitat.

\section{O Rei em farrapos}

O autor finaliza o artigo sobre o homem em farrapos, alegando ser esse o modelo inspirador para a moda requintada e mais estranha na elegância bumana, (...). A moda do trajo em farrapos usada pelo homem e pela mulher ${ }^{15}$ e que durou por muitos séculos. Essas fendas e rasgos que decoravam os trajes das altas classes, deixando à mostra os tecidos das camisas e das calças usadas sob eles, começaram a surgir a partir do século XV, e foram denominadas pelo historiador Carl Köhler ${ }^{16}$ de golpeados.

A teoria sobre a moda dos farrapos, tem continuidade no texto seguinte - O Rei em Farrapos, O Bobo E Os Deuses Moribundos, O Caminho da Linguagem ${ }^{17}$. Neste, Flávio faz analogia sobre o uso do trajo em farrapos pela nobreza e pelo rei, com uma possível identificação desses com as classes mais baixas da população, que, por escassez, obrigatoriamente usavam suas vestes em farrapos.

\footnotetext{
${ }^{11}$ Flávio de CARVALHO. A Moda e O Novo Homem. p. 42.

12 Ibid., p. 43.

13 Ibid., p. 45.

${ }^{14}$ Hilton JAPIASSÚ. Danilo MARCONDES. Dicionário Básico de Filosofia. Verbete: darwinismo. p. 62.

${ }^{15}$ Flávio de CARVALHO. A Moda e o Novo Homem. p. 43.

${ }^{16}$ Carl KOHLER. História do Vestuário. p. 266.

${ }^{17}$ Flávio de CARVALHO. A Moda e O Novo Homem. p. 44.
} 


\section{O decote masculino. Os homens mostram as pernas.}

Flávio de Carvalho investe-se de historiador, ao escrever sobre as origens do uso da moda em farrapos em seu artigo de 31 de maio de $1956^{18}$. O autor observa que, após as revoltas camponesas dos séculos XII, XIV e XV, a população vagava, desabrigada, faminta e em farrapos, impressionando as hierarquias superiores, no caso os soldados que lutavam para reprimir as revoltas populares. Essa maneira de decorar as vestes, rasgando-as nos cotovelos, joelhos e pernas foi incorporada primeiramente pelos soldados alemães quando retornavam à pátria, e posteriormente pelos soldados mercenários. Essa moda então é transportada dos soldados para a nobreza por volta de 1518, perpetuando-se pelos séculos XVI e XVII.

Quanto ao uso do decote nos trajes masculinos, nos séculos XVI e XVII, o autor encontra as origens na mesma situação social que gerou os golpeados, laços e fitas: as revoltas camponesas. Os cortes ombro a ombro, descendo às vezes até o umbigo, na parte da frente e nas costas das vestes masculinas, obrigavam os homens a uma dieta para emagrecer. A moda exigia uma silhueta esbelta e de pele bem tratada, segundo Flávio, que entende ser essa figura masculina magra uma imagem próxima a do faminto maltrapilho, porém de aspecto saudável ${ }^{19}$.

Anne Hollander ${ }^{20}$ comenta que os decotes masculinos que surgem no século XVI, denotavam uma imagem de fragilidade com um acentuado toque erótico passivo, como nos auto-retratos de Albert Dürer de 1493 e 1498 ou pelos modelos masculinos pintados por Ticiano e Giorgione. Para a autora, os colarinhos abertos, ou decotes masculinos, davam aos homens, um forte ar feminino, mesmo aos que usavam barba, sugerindo uma certa vulnerabilidade, contrária aos conceitos de força, bravura e austeridade, definidores do gênero masculino.

\section{As formas fundamentais da mulher}

No subtítulo do artigo de 03 de junho de 1956, o autor complementa com a seguinte frase: Equilíbrio de população e as necessidades da sobrevivência. Para a personagem em estudo, as formas femininas no decorrer dos séculos tiveram dois aspectos fundamentais que ele qualificou de forma curvilinear, e forma em retas paralelas ${ }^{21}$. Ambas estariam ligadas aos períodos da história em que a população estaria em desequilíbrio populacional, ou seja quando a forma curvilinear surge, seria o momento em que haveria uma necessidade de fecundação mais ampla a fim de, (...) ajudar o homem a sobreviver. Essa é uma forma fecundante. Já a forma em retas paralelas é adotada, quando fosse necessário o impedimento do excesso populacional, visando também a sobrevivência da humanidade. Segundo Flávio, essas últimas seriam então formas anti-fecundantes, intelectualizadas e menos convidativas.

Flávio de Carvalho ao analisar as formas curvilineares, levanta a hipótese de que no período em que a população sentia-se ameaçada de extinção pelo aumento da mortalidade, causada por guerras ou grandes moléstias, as configurações femininas surgiam de maneira curvilinear, ou seja as saias tornavam-se amplas. Quando já não havia o perigo desse modo de extinção, surgia um traje para servir de controle da natalidade, ou como ele denominou: anti-

\footnotetext{
18 Ibid., ps. 48 a 50.

${ }^{19}$ Ibid., p. 50.

20 Anne HOLLANDER. O Sexo e as Roupas. A Evolução do Traje Moderno. p. 77.

${ }^{21}$ Flávio de CARVALHO. A Moda e O Novo Homem. p. 51.
} 
fecundante, nesse caso a silhueta feminina surge esguia, com um formato tubular. Na época em que o artigo, com tal hipótese, foi escrito - junho de 1956 - Flávio acreditava que a humanidade estivesse em um período cada vez mais super povoado, e ameaçado pela fome e portanto, estariam sendo abolidas as formas curvilineares numa tentativa de impedir que a espécie desaparecesse pela fome.

\section{A mulher curvilinear - crinolinas}

No artigo de 24 de junho de $1956^{22}$, Flávio de Carvalho faz um estudo sobre o uso das crinolinas $^{23}$ femininas, ou como ele denominou: verdugadas ou cestas. O uso da forma feminina arredondada, para ele, é um retorno ao período primitivo de cio e alegria, encontrada nas esculturas de ídolos e deusas da fertilidade, que têm as pernas, coxas e braços curtos, os quadris volumosos e o torso comprido. Essas mulheres-ídolos ou engaioladas originaram, para o autor, a moda espanhola do século XVI, com suas mangas estufadas (como o hábito encontrado nos povos primitivos de deformar, pelo inchaço, braços e pernas, através do uso de anéis apertados), os quadris salientes provocados pelo uso de cintas (espartilhos) tendo as mãos e os pés pequenos, por conta da imobilidade causada pelo uso dos pesados vestidos da época. Assim, Flávio entende que há uma ligação entre as verdugadas e as imagens de ídolos de fecundidade das remotas épocas da história do homem.

\section{A origem popular da casaca.}

Flávio faz um estudo sobre a evolução da casaca masculina e como essa teria sua ascendência na indumentária do camponês alemão, do século XVI ${ }^{24}$. Até então, as roupas femininas e masculinas eram semelhantes, ou seja, ambos os sexos adotavam a túnica, com ou sem cinto como vestimenta e, por necessidade de maior movimentação para exercer atividades de trabalho, os homens encurtaram suas vestes, o que afetaria a moda masculina para sempre. Registra ele, ser por volta de 1496 o período em que as calças e meias de malhas foram incorporadas pelos homens, permitindo o encurtamento das túnicas. Foi com Luiz XIV (16381715) que a corte francesa adotou a casaca de origem alemã, trazida e usada por aquele monarca, quando tomou para si essa vestimenta usada pelo seu exército.

\section{A origem popular da calça}

O começo do uso das calças, de acordo com Flávio de Carvalho, surge pela necessidade de proteção contra a agressão da natureza e passa então a ser uma vestimenta usada pelos homens, diferenciando-se, assim, das mulheres. As calças surgem das classes hierarquicamente mais baixas e há registros, conforme seus estudos, do uso delas pelos frígios no século VII a.C. e pelos agricultores gregos 500 a.C. Segundo ainda, suas pesquisas, as calças aparecem, também, sendo usadas pelos romanos, gauleses e povos bárbaros nos primeiros

\footnotetext{
22 Flávio de CARVALHO. A Moda e O Novo Homem. p. 58.

${ }^{23}$ Em Laver encontramos a origem do termo crinolina, quando descreve o formato das saias femininas na década de 40 do século XIX. Usavam-se muitas anáguas, e o que se pode ser descrito como o efeito abafador de chá era enfatizado por uma pequena anquinha feita de crina de cavalo. (...) conbecida como "crinolina, (...) crin é a palavra francesa para "crina", (...) material de que as primeiras "crinolinas” eram feitas. James LEVER. A Roupa e a Moda. Uma história concisa. ps 173 e174. ${ }^{24}$ Ibid., p. 89.
} 
séculos de nossa era ${ }^{25}$, sendo que no século XIII essas peças eram feitas em couro e usadas sob os aventais, pelos ferreiros.

Segundo Lever ${ }^{26}$, esse princípio de calça passa a ser adotada pela burguesia já no século XIV juntamente com o gibão, uma jaqueta curta com abotoamento frontal, estreita e bem ajustada, acolchoada na frente de forma a realçar o peito, inicialmente chamada gipon. O gibão era tão justo que muitos o comparavam com as formas do busto feminino, tão curto que causou grande escândalo a ponto dos moralistas da época o denunciarem como peça indecente. ${ }^{27}$ Essa peça foi o divisor de águas entre as túnicas e as jaquetas e responsável pela origem dos coletes e paletós atuais.

\section{Conclusão}

Toma-se aqui, portanto, algumas idéias de Flávio de Carvalho, que serviram de base para seu processo criativo, ao elaborar seu Traje de Verão e, também para uma análise dos papéis masculinos e femininos no momento de sua Experiência $n^{\circ} 3$. Suas reflexões sobre as roupas adornadas com fendas, que, segundo ele, remeteriam aos trajes primitivos, bem poderiam tê-lo inspirado a fazer uma veste de verão com aberturas para a ventilação, como ele mesmo descreve em seu croqui. Por esse aspecto poder-se-ia entender que seu Traje de Verão estaria próximo ao conceito das vestimentas do homem em farrapos, ou seja, seria um retorno ao traje primitivo.

Atente-se para o fato de que o autor foi buscar no universo feminino, todas as peças para compor sua proposta de um novo conceito de moda masculina, como saia, blusa, meias arrastão e até mesmo sandálias, aproximando, assim, os dois gêneros na maneira de vestir. Estaria ele propondo, com essa ação uma volta ao período de Idades Púberes, onde as atividades profissionais começam a se igualar entre os sexos? Importante lembrar, como já abordado anteriormente, que no final da década de 50, do século passado, as mulheres já começavam a ter uma participação mais ativa no mercado de trabalho, não apenas em profissões tipicamente femininas, como educadoras, enfermeiras, domésticas, mas também em atividades, até então, exercidas quase que exclusivamente por homens, como operárias em indústrias ou escriturarias em bancos, por exemplo. Ou apenas, nosso irreverente artista, estava apenas tendo uma atitude provocativa, fazendo uma piada, um chiste, sem maiores pretensões sociais, apenas pelo gosto da polêmica em si, em um gesto que o aproxima ao movimento dadaísta?

Ao observarmos as formas do New Look de Flávio, encontramos semelhanças com aquelas que nosso autor denomina de Formas Fecundantes, pois ambas são largas da cintura para baixo, o que nos leva a um outro questionamento sobre essa ousada proposta de moda masculina: Estaria ele sugerindo que, naquele momento histórico, estivéssemos atravessando um período de necessidade de aumento populacional, ao menos no Brasil? Ou ainda, por estar havendo uma aproximação nos papéis dos gêneros, caberia, então, ao sexo masculino, maior cuidado com o controle da natalidade? Certo é que Flávio de Carvalho, ao buscar peças no guarda-roupa feminino para propor uma vestimenta masculina, estaria de maneira dadaísta, ou

\footnotetext{
${ }^{25}$ Ibid., p. 94.

${ }^{26}$ James LEVER. A Roupa e a Moda. Uma História Concisa. p. 62.

${ }_{27}$ Gilles LIPOVETSKY. O Império do Efêmero. p. 37.
} 
seja, com humor que lhe era característico, questionando o posicionamento de homens e mulheres na sociedade paulistana do final da década de cinqüenta, do século XX.

Por fim, nota-se pelos seus textos, que como a moda é cíclica e reflete grandes mudanças pelas quais a humanidade passa, ao sugerir uma roupa masculina com as características de seu Traje de Verão, Flávio de Carvalho também estaria retornando ao primitivo, ou seja a igualdade entre gêneros utilizando-se das formas fecundantes, em detrimento ao uso de calças, paletós e gravatas, que por 150 anos permaneceram como única indumentária usada pelos homens.

\section{Bibliografia:}

\section{Sobre Flávio de Carvalho e sua obra:}

CARVALHO, Flávio de. A Moda e o Novo Homem. Coletânea de textos publicados no Jornal Diário de São Paulo em 1956. Ed. Senac. São Paulo. 1992.

São Paulo. 1973. - A Origem Animal de Deus e o bailado do Deus Morto. Difusão Européia do Livro, - Fantasias. Desenhos de Flávio de Carvalho. Poemas Kátia Canton. Martins Fontes. São Paulo. 2004.

CARVAlHO, Flávio de Rezende. Os Ossos do Mundo. Antiqua. São Paulo. 2005.

DAHER, Luiz Carlos. Arquitetura e Expressionismo. A Arquitetura de Flávio de Carvalho, anteprojetos e construções entre 1917 e 1947. Pro Editores, São Paulo. 1982.

FREITAS, Valeska. Dialética da Moda: A Máquina Experimental de Flávio de Carvalho. Dissertação de Mestrado. Universidade Federal de Santa Catarina, Centro de Comunicação e Expressão. Florianópolis. 1997.

LEITE, Rui Moreira. Flávio de Carvalho (1899-1973) entre a experiência e a experimentação. Tese apresentada ao Departamento de Artes Plásticas da Escola de Comunicações e Artes da Univesidade de São Paulo. São Paulo. 1994.

OSÓRIO, Luiz Camilo. Espaços da arte brasileira/Flávio de Carvalho. Cosac \& Naify. São Paulo. 2000.

TOLEDO, J. Flávio de Carvalho, Comedor de Emoções. Ed. Brasiliense.

São Paulo. 1994.

\section{Periódicos:}

Correio Paulistano, São Paulo 19.10.56. "New Look na rua Marconi - De calção e blusa o pintor Flávio de Carvalho surpreendeu a cidade com outra experiência".

Diário da Noite, São Paulo 22.10.56. Da Silva, Quirino. Coluna “Notas à Margem”. Flávio, O Tímido.

Folha da Tarde, São Paulo 17.10.56. “O “new look” de Flávio de Carvalho. 
Folha da Tarde, São Paulo 18.10.56. “O artista Flávio de Carvalho fará hoje sua experiência numero três".

Folha da Tarde, São Paulo 19.10.56. "Com saiote e sem vaias, Flavio de Carvalho realizou ontem sua experiência numero três".

O Globo, Rio de Janeiro 16.12.57. "Flávio de Carvalho explica por quê não "pegou” o saiote.

\section{Sobre História, Arte e Comportamento:}

ADES, Dawn. Dada e Surrealismo. Texto da coletânea: Conceitos da Arte Moderna. Org. Nikos Stagos. Trad. Álvaro Cabral. Jorge Zahar Editor. Rio de Janeiro. 2000.

AGRA, Lucio. História da Arte do Século XX; idéias e movimentos. Coleção Moda e Comunicações. Cordenação Kathia Catilho. Editora Anhembi Morumbi. 2004

AMARAL, Aracy A. Arte para que?. A preocupação social na arte brasileira 1930-1970. Itaú Cultural. Studio Nobel. São Paulo. 2003.

AMBURGER, Esther. Diluindo fronteiras: A Televisão e as Novelas no Cotidiano. História da Vida Privada no Brasil. Contrastes da intimidade contemporânea. Vol.4. Coordenação Geral: Fernando A. Novais. Org.do volume: Lílian Moritz Schwarcrz. Companhia das Letras. São Paulo. 1998.

ARCHER, Michael. Arte Contemporânea. Uma História Concisa. Trad. Alexandre Krug e Valter Lellis Siqueira. Martins Fontes. São Paulo. 2001.

BAUDELAIRE, Charles. Escritos sobre arte. Org e tradução Plínio Augusto Coelho. Editora Imaginário. São Paulo. 1998

Idem_ Sobre a Modernidade. Org. Teixeira Coelho. Editora Paz e Terra. Rio de Janeiro. 1996

Idem O Spleen de Paris. Pequenos Poemas em Prosa. Apresentação e Tradução Leda Tenório da Mota. Imago Editora Ltda. Rio de Janeiro. 1995

BARTHES, Roland. Sistema da Moda. Système de la Mode. Trad. Lineide do Lago Salvador Mosca. Companhia Editora Nacional. São Paulo. 1979.

BRAGA, João. História da Moda uma narrativa. Coordenação Kathia Castilho. Coleção Moda e Comunicação. Editora Anhembi Morumbi Ltda.

São Paulo. 2004

CALDAS, Dario, QUEIROZ, Mário. O Novo Homem, Comportamento, Moda e Mercado. texto da coletãnea: HOMENS. org.: Dario Caldas. Ed. SENAC, São Paulo. 1997.

DELEUZE, Gilles. A Dobra. Leibniz e o Barroco. Le pli - Leibniz et le Baroque. Trad. Luiz B.L.Orlandi. Papirus Editora. São Paulo. 2005. 
DUTRA, José Luiz. "Onde você comprou esta roupa tem para homem?”: A Construção de masculinidades nos mercados alternativos de moda. Texto da coletânea: Nu e Vestido, Dez antropólogos revelam a cultura do corpo carioca. Org.: Mirian Goldenberg. Sind. Nac. dos Editores de Livro. Rio de Janeiro. 2002.

FLÜGEL, J.C. A Psicologia das Roupas. The Psychology of Clothes. Trad. Antonio Ennes Cardoso. Editora Mestre Jou. São Paulo. 1966.

FOUCAULT, Michael. Histoire de la sexualité: 1 la volunté de savoir. Trad. Port. História da Sexualidade: (1) a vontade de saber. Albuquerque, Maria Thereza da Costa; Albuquerque, J.A. Guilhon. Graal Ltda. Rio de Janeiro. 2001.

FREYRE, Gilberto. Modos de homem e modas de mulher. Editora Record. Rio de Janeiro. 1986.

GINZBURG, Carlo. Mitos, Emblemas e Sinais. Cia das Letras. São Paulo. 1989.

GLUSBERG, Jorge. A Arte da Performance. Trad. Renato Cohen. Editora Perspectiva. São Paulo. 1987.

HARVEY, John. Homens de Preto. Tradução Fernanda Veríssimo. Editora UNESP. São Paulo. 2003.

HOLLANDER, Anne. O Sexo e as Roupas, A Evolução do Traje Moderno. Trad.: Alexandre Tort. Revisão Técnica: Gilda Chantaignier. Editora Rocco Ltda. Rio de Janeiro. 1996.

KÖHLER, Carl. História do Vestuário. Ediç. e Atualiç.: Emma Von Sichart. Trad.: Jefferson Luis Camrgo. Livraria Martins Fontes Editora Ltda. São Paulo. 1996.

LECHEVALIER-CHEVIGNARD, Edmond. European Costumes of the Sixteenth Through Eighteenth Centuries in full color. Dover Publication, Inc. New York, USA. 1995.

LEVER, James. Costumes and fashion: a concise history. Trad. port. A Roupa e a Moda, Uma História Concisa. Carvalho, Glória Maria de Mello. São Paulo: Companhia das Letras. 1993.

LIPOVETSKY, Gilles. O Império do Efêmero, A moda e seu Destino nas Sociedades Modernas. Trad.: Maria Lucia Machado. Companhia das Letras (Editora Schwarcz Ltda). São Paulo. 2001.

LURIE, Alison. A linguagem das Roupas. Trad.: Ana Luiza Dantas Borges. Editora Rocco. Rio de Janeiro. 1997.

MACEDO, Otávio Roberti. A Vaidade de Todos Nós. Texto da coletânea: HOMENS, org.: Dario Caldas. SENAC. São Paulo. 1997.

MELLO E SOUZA, Gilda. O Espirito das Roupas, A Moda no Século Dezenove. Editora Schwarcz Ltda. São Paulo. 1987.

MENDES, Valerie \& HAYE, Amy de la. A Moda do Século XX. Trad. Luis Carlos Borges. Martins Fontes. São Paulo. 2003.

NOLASCO, Sócrates. O Mito da Masculinidade. Edit.: Rocco Ltda. 
Rio de Janeiro. 1993.

Idem_Um "Homem de Verdade". Texto da coletânea: HOMENS, org.: Dario Caldas. Editora SENAC. São Paulo. 1997.

OSTROWER, Fayga. Criatividade e Processos de Criação. Editora Vozes. Petrópolis. 1987.

POCNA, Marie-France. DIOR. Cosac \& Naif. São Paulo. 2000.

QUEIROZ, Mário. Moda e Corpo, Visões do masculino nos últimos dez anos. Texto da coletânea: $A$ Moda do Corpo O Corpo da Moda. Org. Kathia Catilho; Diana Galvão. Editora Esfera Ltda. São Paulo. 2002.

RODRIGUES, Marly. A Década de 50. Populismo e Metas desenvolvimentistas no Brasil. Editora Ática. São Paulo. 1999.

SALLES, Cecília Almeida. Gesto Inacabado. Processo de criação artística. FAPESP: Annablume. São Paulo. 2004.

SANTAELLA, Lúcia. O Que é Semiótica. Edit. Brasiliense. São Paulo. 1983.

SPENCER, Colin. Homossexualidade Uma História. Hommossexuality a history. Trad. Ruben Mauro Machado. Editora Record. Rio de Janeiro. 1999.

SZMRECSÀNYI, Maria Irene de Q. F. A Metrópole Paulista: 1950-2004. Texto da coletânea: Livros de Valor - História Econômica da Cidade de São Paulo, Org. Tomás Szmrecsányi. Editora Globo, 2004.

VEILLON, Dominique. Moda \& Guerra. Um retrato da França ocupada. La mode sous l'Occupation. Trad. André Telles. Jorge Zahar Editor. Rio de Janeiro. 2004. 